\title{
O ENGAJAMENTO DE INTELECTUAIS EM DEFESA DA ESCOLA NORMAL DE VITÓRIA DA CONQUISTA
}

\section{ENGAGEMENT OF INTELLECTUALS IN DEFENSE OF THE NORMAL SCHOOL OF VITÓRIA DA CONQUISTA}

\section{COMPROMISO DE INTELECTUALES EN DEFENSA DE LA ESCUELA NORMAL DE VICTORIA DE LA CONQUISTA}

Gilmario Moreira Brito ${ }^{1}$ Maria Gamaliélia do Socorro Limeira Coutinho ${ }^{2}$

\begin{abstract}
Resumo: O objetivo deste artigo é analisar o engajamento de professores e jornalistas como intelectuais que defenderam em jornais uma escola Normal para Vitória da Conquista, Bahia. Indaga-se quais as trajetórias formativas e as concepções de educação, ensino e formação de professores dos referidos profissionais? Trata-se de pesquisa qualitativa, baseada na análise de documentos de memorialistas e artigos publicados nos jornais "A Conquista", "O Combate" e "A luta" que veiculavam concepções culturais, educacionais e da política local. Para compreender a história da educação nas inter-relações com abordagens das histórias política e intelectual propostas por Sirinelli (1998) e Alves (2019), discutiu-se as mediações culturais promovidas por intelectuais que pleiteavam a implantação da Escola Normal, ampliando os diálogos com Gramsci (2010), Cruz e Peixoto (2007), Buffa e Nosella (1997), Saviani (2005), Oliveira (2005), Silva (2000), Souza (2010), Medeiros (2008), Pereira (2018) Souza e Casimiro (2010).
\end{abstract}

Palavras-chave: Escola Normal de Conquista. Engajamento. Intelectuais. Mediação cultural. História da educação.

Abstract: The purpose of this article is to analyze the engagement of teachers and journalists as intellectuals who defended in newspapers a normal school for Vitória da Conquista, Bahia. Is it asked what are the training trajectories and the conceptions of education, teaching and training of teachers of the referred professionals? It is a qualitative research, based on the analysis of memorialist documents and articles published in the newspapers "A Conquista", "O Combate" and "A Luta" that conveyed cultural, educational, and local politics concepts. To understand the history

${ }^{1}$ Universidade do Estado da Bahia. Salvador, Bahia, Brasil.

${ }^{2}$ Universidade do Estado da Bahia. Salvador, Bahia, Brasil. 
of education in the interrelationships with approaches to the political and intellectual histories proposed by Sirinelli (1998) and Alves (2019), we discussed the cultural mediations promoted by intellectuals who claimed for the implementation of the teacher training School, expanding the dialogues with Gramsci (2010), Cruz and Peixoto (2007), Buffa and Nosella (1997), Saviani (2005), Oliveira (2005), Silva (2000), Souza (2010), Medeiros (2008), Pereira (2018), Souza and Casimiro (2010).

Keywords: Normal School of Conquista. Engagement. Intellectuals. Cultural mediation. History of education.

Resumen: El propósito de este artículo es analizar la participación de maestros y periodistas como intelectuales que defendieron en los periódicos una escuela Normal para Vitória da Conquista, Bahía. ¿Se pregunta cuáles son las trayectorias de formación y las concepciones de educación, enseñanza y formación de los docentes de los referidos profesionales? Es una investigación cualitativa, basada en el análisis de documentos memorialistas y artículos publicados en los periódicos "A Conquista", "O Combate" y "A Luta" que transmitían conceptos de política cultural, educativa y local. Para comprender la historia de la educación en las interrelaciones con enfoques de las historias políticas e intelectuales propuestas por Sirinelli (1998) y Alves (2019), discutimos las mediaciones culturales promovidas por intelectuales que abogaron por la implementación de la Escuela Normal, ampliando los diálogos con Gramsci (2010), Cruz y Peixoto (2007), Buffa y Nosella (1997), Sirinelli (1998) (2005), Oliveira (2005), Silva (2000), Souza (2010), Medeiros (2008), Pereira (2018), Souza y Casimiro (2010) .

Palabras clave: Escuela Normal de Conquista. Compromiso. Intelectuales. Mediación cultural. Historia de la educación.

\section{INTRODUÇÃO}

Para compreender o engajamento e a contribuição de intelectuais de Vitória da Conquista que se manifestaram na imprensa escrita para discutir e participar do processo de reivindicação e implantação da Escola Normal recorreu-se as concepções formuladas por Gramsci³ (2010, pp. 1819) que situa o intelectual no lugar desempenhado no processo histórico, e coloca seu "modo de ser" em uma [...] "inserção ativa na vida prática, como construtor, organizador, persuasor permanente". Em seguida, considera que os intelectuais são integrantes das relações sociais de uma classe social e representa os interesses dessa classe no conjunto da vida social. Nesse sentido,

Formam-se assim, historicamente, categorias especializadas para o exercício da função intelectual; formam-se em conexão com todos os grupos sociais, mas, sobretudo em conexão com os grupos sociais mais importantes, e sofrem elaborações mais amplas e complexas em ligação com o grupo social dominante. (GRAMSCl, 2010, p. 18-19)

Antonio Gramsci, desenvolveu suas reflexões sobre "Os intelectuais. O princípio educativo" nos Cadernos do Cárcere, escritos entre 1926 e 1937. 
As considerações do autor dão pistas para compreender como se constituíram historicamente os jornalistas que atuavam em Conquista desde 1911 até meados do Século XX, como categoria profissional, seja na condição de proprietário, jornalista, editor e colaborador de jornais pertencentes a líderes políticos, como os coronéis Gugé e Deraldo Mendes que utilizavam estas mídias para assegurar seus postos na política local e ampliar suas visibilidades. Assim é perceptível o exercício realizado por intelectuais especializados na produção e mediação da cultura escrita e impressa "na conexão" com "outros grupos mais importantes" que se tornaram responsáveis pela organização do discurso do poder porque os sustentava. Todavia, no que pese suas contradições, suas atuações eram "mais amplas e complexas", não se encerravam apenas naquele lugar de reprodutores do poder instituído, já que defenderam também reivindicações da classe social a que pertencia: a construção e o funcionamento de uma Escola Normal imaginando que a instituição poderia inserir e equiparar a cidade a centros urbanos modernos, lugares de progresso e desenvolvimento. Nesse sentido, realizavam de acordo Gramsci (2010, p. 23) uma grande função político-social, já que "a mediação profissional dificilmente se separa da mediação política".

Nas últimas décadas, outros estudiosos têm retomado a discussão sobre a importância dos intelectuais para outros campos da história. Sirinelli (1998, p. 259) identificou que "havia possibilidade de estudar a história de intelectuais fazendo ligações da história política com a história cultural" e nas recentes reflexões, Alves $(2019$, p. 2) retoma a proposta teórico-metodológica da história dos intelectuais indicada por Sirinelli para pensar suas relações com a história da educação: "voltada para as relações entre a história dos intelectuais e a história da educação", ao tempo que alerta para o cuidado que a pesquisa histórica deve tomar "quando se propõe a investigar intelectuais da educação no Brasil".

\section{PROFESSORES E JORNALISTAS: INTELECTUAIS CRIADORES E MEDIADORES CULTURAIS EM VITÓRIA DA CONQUISTA DE 1930 A 1950}

Recorrendo a fontes escritas e impressas (jornais, revistas, livros de memórias e biografias) identificamos grupos sociais que atuavam como professores, escrivães, letrados que ao lado da narrativa "eloquente" dos contos, crônicas e poesias, também realizaram, de acordo Gramsci uma [...] "inserção ativa na vida prática" ao participar dos debates entre as décadas de 1930 e 1950 por uma Escola Normal e se tornarem, para usar a sugestão de Sirineli (1998), reconhecidos pela sociedade como intelectuais nos espaços de representação social e política de Vitória da Conquista. 
Nas publicações impressas, encontramos professores que se tornaram referências fundamentais na educação do município. Identificamos e sistematizamos manifestações escritas, publicadas pelos professores e jornalistas Laudionor de Andrade Brasil, Euclides Abelardo Dantas, entre outros, que produziram narrativas de vários gêneros, prestando significativas contribuições à implantação da Escola Normal em Vitória da Conquista. Nesse sentido, se constituíram como "sujeitos" na escrita da história da educação da cidade e ganharam evidência na concretização daquele projeto. Tornaram-se sujeitos públicos, reconhecidos por grupos com os quais mantinham diálogos ao defender que o progresso da nação deveria tomar como referência a educação dos moradores da cidade.

A leitura dos documentos revela que os referidos intelectuais se destacaram no campo da educação e da cultura, deixando marcas de atuação como professores, poetas, jornalistas e políticos, possuidores de prestígio social, que iam sendo reafirmado por meio de escritos e discursos publicados em jornais defendendo interesses dos grupos que se relacionavam. Suas ações foram responsáveis por manter e atualizar expectativas, na medida em que seus argumentos foram ganhando densidade política por longo tempo, incorporando-se à história da cidade e dos professores. Reconhecidos como "lugares de memória" para usar a expressão de Nora (1993) são revisitados, recuperados na biografia da cidade em manifestos de intelectuais locais e na exaltação dos nomes rememorados em vários lugares da cidade: ruas, praças, escolas e centro cultural.

É importante registrar, no contexto do período mencionado, que havia de acordo Pereira (2018, p. 238) múltiplas dimensões e intencionalidades, de maneira a solucionar questões educativas no âmbito do ensino-aprendizagem, da relação educação e sociedade, das contradições entre o capital, o trabalho e a educação. Todavia, os intelectuais mencionados, que atuavam como jornalistas e educadores, defendiam que a instrução deveria ser ministrada à juventude com o objetivo de fomentar o nacionalismo e de combater o estrangeirismo: avaliavam que só pela educação era possível salvar a pátria. Nesse sentido, apontavam que o currículo deveria se basear no ensino da língua, na história e na geografia do Brasil para construir as bases da identidade nacional.

A esse respeito, Buffa e Nosella (1977, p. 54) consideram que o fervor ideológico foi ganhando força política com o processo de modernização da identidade nacional do Brasil. Os educadores envolveram-se como uma categoria profissional que, em certo sentido, assimilou o discurso e promoveu exercícios que objetivavam a modernização o ensino. Com esse fim, os intelectuais Sampaio Dória, Anísio Teixeira, Lourenço Filho, Fernando de Azevedo, Carneiro Leão, 
entre outros, efetuaram reformas em vários Estados brasileiros na década de 1920 apresentando suas propostas pedagógicas.

É interessante notar que, segundo Saviani (2005, pp. 33 e 34), em 1932 os intelectuais da Associação Brasileira de Educação lançaram o Manifesto dos Pioneiros da Escola Nova que, dentre outras exigências, trazia a defesa da escola pública, uma proposta que influenciou na elaboração do texto da Constituição de 1934, apesar de estar dividido em posições contrárias (liberais x católicos), também enfatizaram a preocupação com a formação de professores.

É nesse contexto de transformação da educação brasileira, a partir dos anos de 1930, que verificamos nas fontes escritas - livro de atas da Câmara Municipal, jornais e biografias-, entre 1932 e 1937, que havia em Vitória da Conquista maior disposição de participação nos espaços de discussão política. Assim, as contendas em torno da Escola Normal receberam novo impulso, sobretudo após a renovação no debate nacional polarizando católicos e escola-novistas. As fontes consultadas, principalmente os jornais, evidenciaram que a implantação de uma escola para formação de professores era defendida como signo de modernidade e de progresso para a cidade.

Em Conquista o jornal "O Combate", inaugurado em 11 de agosto de 1929 por Laudionor Brasil, noticiava fatos marcantes da sociedade, do estado e acontecimentos do cenário nacional e internacional. De acordo Oliveira (2005, p. 168), pela qualidade do jornalismo da época, “O Combate" tinha boa aceitação dos leitores. Era um veículo sustentado por anunciantes constituídos por comerciantes da praça, mas o jornal se declarava como semanário independente e noticioso que circulava aos domingos.

Apesar da importância do jornal "O Combate", oficialmente o primeiro semanário da cidade foi "A Conquista". Era uma mídia de comunicação que pertencia ao Partido Democrático, e depois, do Republicano Conservador, que mais tarde, passou para a direção de Climério Pinto e Hormindo Cunha. O jornal impresso no formato do tipo tabloide era mais político do que noticioso, com artigos e comentários sempre nas primeiras páginas.

Outro jornal era "A Luta", se autointitulava de semanário independente, literário e noticioso, fundado por Luiz Gonzaga Bastos, foi posto em circulação em 30 de maio de 1936. Apesar de anunciar que era "independente", esse meio de comunicação se empenhava para dar visibilidade e suporte ideológico ao grupo político da situação, liderado pelo Coronel Deraldo Mendes. O redatorchefe do referido jornal era o professor e jornalista Euclides Dantas que ganhou enorme destaque e reconhecimento pelo incansável trabalho de articulação entre políticos de Salvador e Conquista 
no processo de implantação da Escola Normal. Seu nome foi consagrado na memória da cidade, virou "lugar de memória" com a denominação da Escola de Instituto de Educação Euclides Dantas.

Os jornais mencionados "A Conquista", "O Combate" e a "A Luta",", além de publicar notícias e informações sobre política, economia e sociedade, também prestaram grande contribuição ao veicular notas, opiniões e debates sobre educação e a cultura, por isso, constituem-se em importantes fontes de estudo nas quais foi possível localizar opiniões e discussões de intelectuais e professores. Apesar de os jornais não serem o objeto deste artigo, mas os referidos produtores, é importante entendê-los como manifestações de linguagens que constituem as relações sociais da cidade cuja historicidade "requer ser trabalhada e compreendida como tal, desvendando, a cada momento, as relações imprensa /sociedade, e os movimentos de constituição e instituição do social que esta relação propõe" (CRUZ e PEIXOTO, p. 258).

É importante considerar que Laudionor e Euclides Dantas faziam parte da produção dos jornais na condição de colaboradores, colunistas, redatores, diretores e assíduos leitores. Era dos lugares que ocupavam nessas mídias que publicavam as concepções políticas relacionadas aos valores e juízos morais a partir dos quais apontavam projetos e caminhos que almejavam para a sociedade conquistense, dentre os quais foi possível acompanhar aquelas notícias e temas relacionados a educação.

No contexto do primeiro governo Vargas (1930-1945), como ressalta Silva (2000, pp. 87-88), o intelectual representado como professores, jornalistas, advogados e missivistas assumiram posições destacadas e almejadas, tanto em âmbito nacional, quanto regional e local, porque dispunham de meios técnicos e intelectuais capazes de intervir diretamente na comunidade, através de atividades políticas, do acesso e da operação dos próprios meios de comunicação.

Conquistar o lugar de intelectual que possibilitava a aquisição de um status junto a sociedade foi também defendido por professores que desejavam ocupar os espaços facultados por essa titulação. A construção dessa visibilidade começava pela imprensa, - o principal meio de divulgação de produção intelectual -, que além de abrir as portas para cargos públicos e para o ingresso na política, compensava pela projeção social que proporcionava, ainda que o retorno financeiro fosse pouco significativo. $\mathrm{O}$ acesso ao jornalismo se dava a partir de indicações de amizade, simpatia, filiações políticas etc., e eram posições ocupadas por professores, advogados, médicos, engenheiros, literatos. Além da imprensa,

\footnotetext{
${ }^{4}$ Jornais preservados no acervo particular do Prof. Dr. Rui Herman Medeiros que os disponibilizou para esta pesquisa.
} 
[...] as salas de aula consistiam em locais cobiçados e importantes. Ser professor secundário possuía suas vantagens. Era um ensino destinado às elites. Assim como a imprensa, o ensino facilitava o acesso aos estratos dirigentes e mantinha atualizados os contatos entre os seus membros. (SILVA, 2000, p. 88)

No sentido apontado por Silva é possível compreender que o professor e a professora a ser selecionado para ministrar aulas na Escola Normal precisava se dirigir a seus alunos e alunas nas salas de aula e também recorrer a outros meios de comunicação e suportes de linguagens que lhe eram tanto colocados à disposição quanto inventados no cotidiano da escola como condição mínima e necessária para exercer sua profissão e assim se legitimar como categoria. Mas, não custa lembrar que o exercício da intelectualidade, muitas vezes, o levava a ocupar outros espaços e cargos, na burocracia do Estado, designados por representantes e correligionários políticos interessados em defender, mais seus interesses privados, do que as políticas públicas. Além de executar os compromissos, também buscavam reconhecimento dos pares e da sociedade de Conquista para si próprios. Nesse processo, com o objetivo político de expandir a visibilidade de sua condição de intelectual, foram se organizando em agrupamentos literários, alas, grêmios que os proporcionavam publicar em revistas literárias capazes de garantir e aumentar o respaldo perante a outros grupos sociais da população.

Vale ressaltar, os jornalistas e professores tratados, neste artigo, como intelectuais que se manifestaram sobre a implantação da Escola Normal ficaram conhecidos no município, segundo Souza (2010, p. 141), desde os anos de 1930, como protagonistas da imprensa, juntamente com outros colaboradores nos jornais, que eram quase a única opção de manifestação e acesso à cultura impressa. Os referidos intelectuais e escritores tinham dificuldades para publicar seus textos devido à falta de editoras e os jornais se apresentavam como uma possiblidade de alimentar um certo "fórum literário" com certo amadorismo. Diante de empecilhos de publicar em livros, letrados recorriam aos jornais tendo em vista alcançar visibilidade e notoriedade para suas produções e se possível, um "pouco de dinheiro".

É possível compreender que os intelectuais acima mencionados foram assim considerados porque colocaram em discussão problemas e concepções relacionadas a educação na cidade. Nesse sentido, conforme Alves (2019) dialogando com Sirinelli (1994, p. 9) tornaram-se tanto criadores como mediadores culturais já que, ao mesmo tempo que veiculavam ideias que circulavam em nível nacional, difundindo, mesmo em suas contradições, também se posicionava a favor da modernização do ensino e pelo fim do analfabetismo, levantando o lema republicano de ordem e de progresso, de exaltação da nação e da moral cívica. É importante registrar que os intelectuais 
mencionados não chegaram a ser professores da Escola Normal de Conquista, mas, ao defenderem um ideário educacional, colaboraram de forma significativa para a sua implantação.

\section{INTELECTUAIS ENGAJADOS NA DEFESA DA ESCOLA NORMAL: ITINERÁRIOS, PARTICIPAÇÃO POLÍTICA E SOLIDARIEDADE}

A partir das matérias e notas publicadas em jornais de Vitoria da Conquista, compreendemos que os intelectuais considerados, principalmente, como professores e jornalistas envolvidos com a educação mantinham um engajamento com a cidade já que, de acordo Sirinelli (1998) "participavam ativamente" no processo de reivindicação e implantação da Escola Normal, posteriormente denominada de Instituto de Educação Euclides Dantas.

Nesse sentido, recorremos tanto a pesquisas de Sirinelli (1998, p. 259) que indicou a "possibilidade de estudar a história de intelectuais fazendo ligações da história política com a história cultural", quanto da interpretação da obra apresentada por Alves (2019). Em sua análise (Alves, 2019, p. 2) identificou as contribuições do referido autor para pensar "as relações entre a história dos intelectuais e a história da educação" indicando chaves de leitura que colaboram, tanto para analisar o itinerário dos intelectuais Laudionor Brasil e Euclides Dantas que prestaram relevantes contribuições a história local e regional, estão presentes em lugares de memória da cidade, mas de alcançaram menor visibilidade na escrita da História da educação.

Alves (2019, p. 3-4) observa que os intelectuais podem ser considerados como "os sujeitos envolvidos com atividades laborais associadas ao escrito" que assumem a condição de "criadores", "mediadores" quando estão envolvidos no "engajamento" que demanda uma "participação coletiva". Em artigos publicados nos referidos jornais por intelectuais envolvidos na defesa da implantação da Escola Normal foi possível observar que as categorias "produção, mediação e engajamento" acima apontadas, contribuíram para analisar os lugares assumidos pelos intelectuais envolvidos na produção de narrativas em defesa da Escola porque estavam cotidianamente implicados com as letras na condição de professores e jornalistas.

Em outra sugestão de pesquisa sobre intelectuais Alves (2019, p. 5) aponta três chaves de observação e análise "itinerários intelectuais, redes de sociabilidade e geração" compreendendo-as como categorias interrelacionadas entre si. As leituras e as sugestões de Sirinelli e Alves contribuíram para discutir e analisar as trajetórias formativas, o envolvimento laboral com as letras, a participação política, a criação de produtos culturais, a sociabilidade e as tensões entre Laudionor Brasil, Ernesto Dantas e outros intelectuais da cidade, observando as agregações em torno dos 
jornais, o engajamento em torno da educação e, especialmente, na defesa da Escola Normal de Vitória da Conquista.

É necessário esclarecer que os intelectuais tratados nesse artigo não possuem a formação escolar dos tradicionais bacharéis, acadêmicos e "doutores" tão celebrados e que receberam destacada visibilidade nos meios de comunicação e acadêmicos do país. De acordo Viana (1982, p. 171), Laudionor de Andrade Brasil, nasceu em 13 de fevereiro de 1901, em Vitória da Conquista, filho do carpinteiro Manoel de Sena Brasil e Henriqueta Andrade Brasil, iniciou os estudos primários em 1907 que se estendeu até 1910, na escola pública da professora Honorina Andrade onde concluiu o terceiro ano primário e começou a trabalhar como balconista em casas comerciais da cidade desde criança até 1920. Ainda de acordo Viana (1982, p. 225), desde cedo mostrou sua vocação para as letras, gostava muito de livros.

Nesse período, foi aprendiz na alfaiataria de Otávio Moreira e permaneceu nesta função até 1922, quando foi convocado a prestar serviço militar em Maceió (Alagoas). Apesar de trabalhar na alfaiataria e depois no comércio é importante ressaltar que desde 1918, Laudionor já publicava poesias no Jornal "A Palavra", cujos redatores eram os professores Ernesto Dantas Barbosa e Euclides Abelardo de Souza Dantas, indicando que eles já construíram aproximações pelas culturas escrita e impressa. Ainda de acordo Viana, em 1920, Laudionar ainda envolvido com o mesmo labor, propôs e fundou com outros colegas o Grêmio Dramático Castro Alves, um espaço que abrigava jovens considerados letrados e intelectuais da cidade, cujo objetivo era dar visibilidade a produção cultural de recitais de poesias, apresentação de corais, de peças teatrais e de filarmônicas. Pode-se depreender que articulação das referidas artes e das manifestações culturais em um mesmo espaço, também era fértil às discussões políticas.

Quando retornou de Maceió, em 1924, Laudionor foi trabalhar em lojas estabelecidas no comércio da cidade e posteriormente, em meados da década de 1920 conseguiu se inserir na educação como auxiliar de ensino e, anos mais tarde, tornou-se diretor do Educandário Sertanejo, estabelecimento que pertencia ao professor Euclides Dantas. Depois da experiência como diretor Laudionor Brasil (1932, p. 1) montou sua própria escola: O Externato Brasil, colégio de ensino primário, situado ao lado da tipografia de "O Combate", jornal que ele fundou em 1929, aos 28 anos, conquistou ampla repercussão e passou a ser o jornal mais importante de Vitória da Conquista entre as décadas de 1930 a 1964. Portanto, vê-se na trajetória deste letrado que buscou se engajar na cultura da cidade pelas artes, educação e jornalismo indícios de como foi articulando, ao longo de 
sua vida, os lugares públicos de criação cultural direcionando-os para a educação voltada para o ensino e/ou aquisição e gestão escolar.

De acordo Souza e Casimiro (2010, p. 2), Laudionor Brasil não era adepto do Partido Comunista, criado e liderado por Luiz Carlos Prestes em 1920, nem defendia uma revolução socialista, mas era favorável ao fim da exploração dos menos favorecidos, das lutas populares, de uma sociedade justa e igualitária aos moldes da fraternidade cristã e como era católico fervoroso, acreditava que essas conquistas viriam através do caminho da educação. Porém, é possível observar algumas contradições em seu discurso, em que pese defender princípios republicanos, elegeu o progresso numa perspectiva teleológica, um conceito positivista em torno do qual todas as ações deveriam ser direcionadas para se estabelecer a ordem que, deveria ser respeitada e cumprida. Embora fizesse crítica a riqueza proveniente das elites que monopolizavam o poder e declarasse repugnância a todas as formas de ditadura e de opressão, foi veemente defensor de Getúlio Vargas que articulou o golpe e instalou a ditadura do Estado Novo. Por outro lado, defendia a educação moderna e as ideias liberais, bandeiras que utilizou para se inserir e se engajar nas 'lutas' de moradores de Conquista, dentre as quais a defesa da implantação da Escola Normal que Ihe possibilitou ascender socialmente e adquirir prestígio social na cidade.

Foi mantendo essa postura contraditória que, juntamente com outras pessoas, fundou o Partido Liberal conquistense e ao lado do coronel Deraldo Mendes defendeu a candidatura de Vargas em 1930, redigiu o manifesto do Partido Liberal apoiando a revolução de 30, da mesma forma que publicou um livro de crônicas e poesias intitulado: "De lenço vermelho: crônicas em defesa da aliança liberal", em coautoria com o jornalista Bruno Bacelar de Oliveira.

A respeito de Laudionor e outros intelectuais inseridos nas disputas políticas de Conquista, Sousa e Borborema (2001, pp. 225-236) enfatizam que suas atuações não se restringiam apenas à exaltação do partido liberal, de seus líderes, seus discursos etc., mas, recorria aos jornais, publicava artigos que criticavam os governos e a oposição, tanto em nível local como nacional. Vai ficando claro que as manifestações de apoio a educação ganham contorno da cultura e do posicionamento político assumido por intelectuais de Conquista frente ao Movimento de 1930, Medeiros (2008) afirma que nesse contexto, assim como no restante do país, acirraram-se as disputas partidárias.

Em outra aproximação com a história da educação é perceptível o esforço dos intelectuais em ampliar a "produção" e a "mediação cultural" para outros segmentos culturais da cidade que não estavam envolvidos apenas com as escolas, segundo Medeiros (2008), Clóvis Lima, Euclides Dantas, Camillo de Jesus Lima, Erathóstenes Menezes e Laudionor Brasil, dentre outros, 
professores, jornalistas e advogados, considerados intelectuais e reconhecidos pela cidade, fundaram a Ala de Letras de Conquista que publicou em novembro do mesmo ano o livro "Vinte anos de amor e de tortura". A implantação da "Ala" representou a organização de um espaço muito importante para os letrados da cidade, conferia uma nova feição e reconhecimento a produção e circulação da literatura local, proporcionava contato com letrados de outros lugares, dava oportunidade a divulgação da produção cultural e manteve os participantes atualizados quanto às mudanças da literatura em âmbito regional.

Notícias que enfocavam a educação e, principalmente, o combate ao analfabetismo e a instalação de uma Escola Normal para formação de professores estiveram presentes em várias manchetes e artigos desse jornal, desde os anos de 1930. Verificamos no semanário "O Combate", que o próprio Laudionor Brasil escreveu um artigo no dia 6 de novembro de 1932 com o título: “A Escola Normal: é possível que, agora, Conquista realize a sua grande aspiração".

Os nossos amigos Dr. Francisco Bastos, prof. da Escola Normal de Caetité, e o prof. Euclydes Dantas, diretor do colégio "Marcellino Mendes" desta cidade, por intermédio do Snr. Cel. Deraldo Mendes Ferraz, Prefeito da Comuna, estão pleiteando junto ao eminente Interventor Federal do Estado, Tenente Juracy Magalhães, alguns favores para a criação e funcionamento nesta cidade duma Escola Normal equiparada, como possuem Ilhéus, a Cidade da Barra e a Capital do Estado.

Tivemos o prazer de ver as cláusulas constantes da proposta que vai ser enviada ao Governo do Estado e julgamos justíssimas as pretensões daqueles cavalheiros e não duvidamos que eles sejam bem-sucedidos, em vista da boa vontade já conhecida do Interventor do Estado em relação à criação duma Escola Normal em Conquista (BRASIL, 1932, p. 1).

Mais uma vez, a leitura atenta do recorte do semanário informa sobre o processo de mobilização de diretores, políticos da cidade e do estado para a implantação da Escola Normal. Chama a atenção o argumento apresentado pelo intelectual Laudionor ao interventor Juracy Magalhães, de prestar o favor para "criação e o funcionamento nesta cidade duma Escola Normal". A negociação da criação e funcionamento da Escola foi realizada em meio ao jogo político do estado dirigido por um interventor que postulava se manter no cargo e na possível eleição de 1938 pleitear concorrer à presidência da república. A apelação era a mesma usada nos acordos políticos entre os coronéis e a oligarquia baiana: o favoritismo.

O jornal "O Combate" foi um meio de comunicação que, talvez pela trajetória e engajamento de Laudionor nos clamores da cidade, organizou mediações e incentivou a implantação da Escola Normal, noticiou a criação de uma comissão para, reivindicar uma Escola Normal junto ao interventor federal Juracy Magalhães, que mantinha fortes vínculos políticos e laços de amizade com o coronel e prefeito Deraldo Mendes do qual recebeu o apoio político e financeiro. Ou seja, o 
pleito da Escola estava profundamente inserido na cultura política do município e do estado e mantinha fortes vínculos com a troca de favores entre o coronel da região e o tenente do movimento civil-militar de 1930 travestido de oligarca.

Trocando em miúdos, o interventor deveria retribuir um "favor" ao coronel-prefeito. Ao usar o seu poder político para favorecê-lo, intercederia para eliminar os entraves políticos e burocráticos tendo em vista a implantação da escola normal em Vitória da Conquista. Apesar de a "Revolução 1930" como movimento político-militar ter chegado ao poder defendendo colocar fim no sistema oligárquico, na Bahia o tenente interventor, alimenta pretensões de se manter no poder trocando favores políticos com coronéis do interior da Bahia.

No processo de articulação, o intelectual, jornalista e professor Euclides Dantas também transitava junto aos políticos pleiteando a escola, em seu discurso alegava que as cidades de Ilhéus, Barra e a capital já possuíam uma Escola Normal, e que a cidade de Vitória da Conquista também necessitava de uma Instituição para formação de professores.

Em outra matéria, Laudionor prossegue repercutindo a necessidade da escola normal para Conquista, mostrando a importância de seu jornal para o progresso.

Jornal inteiramente dedicado a tudo o que interessa ao progresso desta terra, "O Combate" não pode silenciar sobre o caso. E, enaltecendo a ideia daqueles nossos amigos, fazemos votos os mais sinceros para que consigam realizar o seu desiderato, na certeza de que eles, com a realização do seu projeto, vão prestar, não somente à Conquista, mas a todos os municípios circunvizinhos, o mais relevante serviço. (BRASIL, 1932, p. 1).

O jornalista chama a atenção dos leitores e da população para a importância da implantação e do funcionamento de uma escola normal em Vitória da Conquista, núcleo de uma região que agrega os municípios de Itambé, Encruzilhada e Poções, na medida que apoia e enaltece a mobilização dos professores Euclides Dantas e Francisco Bastos, que preocupados com a educação e a formação de professores na região, se deslocaram até Salvador, a capital do estado para sensibilizar outros políticos e intelectuais ligados ao Instituto Geográfico e Histórico da Bahia para Ihes solicitar a contribuição acadêmica de reforçar o pedido ao interventor do estado da Bahia para a instalação da instituição voltada para a formação de professores no município.

O apelo dos intelectuais ao poder político tinha o propósito de apresentar evidências pedagógica e científica para justificar a importância da implantação de uma escola normal voltada à profissionalização do professor que ao adquirir competências didáticas poderia formar melhor aos filhos que dispunham de menos recursos, evitando que estes se deslocassem para outras cidades e 
estados para estudar. Ampliava ainda mais a justificativa reafirmando que o estabelecimento poderia favorecer as sociedades de conquista e de outras cidades circunvizinhas.

O processo de engajamento, produção de documentos, artigos, justificativas, organização e articulação com políticos e colegas do IGHB desencadeado pelos mencionados intelectuais na defesa da escola era mais amplo, havia, no fundo a busca por um projeto modernizador da sociedade que passava, entre outras demandas, pela formação de professores que seria viabilizada com a implantação de uma escola normal capaz de orientar a cidade em direção do desenvolvimento e do progresso. Nesse sentido, conforme Buffa e Nosella (1997, p. 67) estavam sintonizados com os partidários da Escola Nova empenhados em definir "o sentido pedagógico da Revolução de 30"

Seguindo na luta em favor da Escola, na matéria a seguir, Laudionor procura mostrar que a inexistência da escola normal, ocasionava desvantagens e prejuízos a cidade de Conquista, para ele A falta dum estabelecimento de ensino dessa natureza nos traz um incalculável prejuízo, pois, a instrução primaria, base única do progresso, não poderá ser satisfatoriamente difundida nesta zona, enquanto não tivermos uma Escola Normal para a formação de professores naturais não só das sedes dos municípios a que nos referimos como dos seus distritos, pessoas que, habituadas com o meio em que nasceram e viveram, trabalharão com inteiro interesse no seu árduo mister (BRASIL, 1932, p. 1)

Os intelectuais professores, que foram à capital do Estado com o propósito de conseguir apoio para abrir um estabelecimento de ensino para formação de professores em Conquista sabiam da necessidade de qualificar profissionais do sertão que, na maioria, eram professores leigos, provenientes da zona rural do município. Para os intelectuais, a criação da escola normal, era capaz de formar em poucos anos profissionais capacitados para atuar na educação primária, e poderia fornecer a base, o alicerce de uma cidade desenvolvida, moderna, evoluída e ajustada às solicitações da civilização. Uma escola com esse perfil poderia oferecer os elementos formativos necessários para acompanhar o progresso do país e levar as luzes aos saberes do sertão.

Para além dos marcadores imaginários e ideológicos, os intelectuais ampliavam a justificativa argumentando que se a cidade fosse atendida com a implantação dessa escola, 0 governo do estado evitaria prejuízos porque não necessitaria contratar profissional da capital, pouco habituado a trabalhar no interior, principalmente em distritos localizados na zona rural do município. Assim, a escola poderia incentivar a formação normal de professores leigos para atuar, futuramente, depois de qualificados, em seus próprios lugares de origem na região. Para concretizar o projeto de modernização, nada mais coerente que iniciar pelo elemento fundamental do processo educacional: a formação do professor. 
No contexto de discussão nacional sobre a educação que envolvia os meios de comunicação do país e intelectuais propositores da Escola Nova, Laudionor Brasil dá sinais de estar envolvido nesse processo, para enfatizar a importância da educação em Vitória da Conquista, além das publicações de sua autoria, estimulava outros intelectuais a manifestarem suas opiniões produzindo artigos. Em 1935 publicou matéria de Mário Padre ${ }^{5}$ no jornal "O Combate", na qual o professor apresenta a necessidade de implantação da escola normal como instituição fundamental do processo de "evolução pedagógica" desencadeado pelos pioneiros,

a partir da república, há uma evolução pedagógica no Brasil, baseada nas propostas de Lourenço Filho, Fernando de Azevedo e Anísio Teixeira, dentre outros. [...] Esses educadores defendiam novos métodos de ensino e combatiam o modelo de escola antiga, e, ainda, que a construção de uma escola nova, pautada na escola primária é base de todo progresso, significando um futuro feliz. (PADRE, 1935, p. 1)

Defensor de uma pedagogia moderna orientada pelos princípios defendidos pelos pioneiros - isto é, educação pública, laica e a coeducação-, Padre considerava que só a educação do povo podia resolver as mazelas do país. Partindo desse pressuposto afirmava que "O homem analfabeto" se constitui em obstáculo à construção da nação, a solução para superar esse impasse era "a construção de uma escola nova pautada na escola primária" que a seu juízo "é base de todo progresso", para tanto a implantação da Escola Normal era de fundamental importância para orientar com referências pedagógicas atualizadas e "novos métodos de ensino" a formação de professores.

As manchetes sobre educação foram se intensificando. É possível identificar que Laudionor Brasil articulava e garantia a publicação de artigos em seu jornal redigidos por outros intelectuais e colaboradores envolvidos na defesa da educação. Tal postura foi importante para alimentar um debate sobre a educação. Nesse sentido, Laudionor revelou-se como um intelectual engajado em questões educacionais, culturais e políticas da cidade, transformou o semanário "o Combate" mais do que um meio de comunicação, o colocou à disposição da mediação cultural, como um suporte de práticas sociais e linguagens que cumpriu um o ideário de contribuir na formação intelectual de jovens escritores conquistenses da época, e oferecer as instalações do jornal para servir de sede para reuniões e atividades da Ala de Letras.

Talvez, seja importante indagar por que Laudionor Brasil se tornou um intelectual preocupado com a educação inserida no processo de implantação das concepções republicanas na cidade, demarcando sua atuação em diversos espaços, na direção da escola, na sala de aula, na 
imprensa, nas agremiações literárias, na política, cujas ações possibilitaram que ocupasse lugar social de referência e ascendesse socialmente? É importante ressaltar que ele era oriundo de uma família pouco abastada, que teve acesso apenas ao primário incompleto, essas duas constatações indicam que em sua trajetória de vida os ganhos e conquistas foram, em grande medida, alcançados mediante permanente labuta por autonomia, promovida por um exercício de acesso a bens culturais e a cultura escrita reafirmado no pleno exercício do autodidatismo em um contexto de uma sociedade em transformação. Mas, não estava só nesse percurso, outros professores e jornalistas que alcançaram visibilidade na cidade apresentavam trajetórias formativas semelhantes.

De acordo Souza e Casimiro (2010, p. 13), Laudionor Brasil faleceu em 14 de março de 1950, durante os anos seguintes recebeu homenagens póstumas, em 1960 uma solenidade rememorou os dez anos de falecimento, recebeu uma escultura com busto assentado no Instituto de Educação Euclides Dantas com a finalidade de reafirmar uma memória de reconhecimento da cidade pela inestimável colaboração à cultua, política e educação, notadamente, para a implantação da Escola Normal.

Logo após a inauguração, a Escola Normal recebeu o nome de Instituto de Educação Euclides Dantas, uma homenagem prestada a esse jornalista e professor que nasceu em Salvador em 1888 e chegou em Vitoria da Conquista em 1911, dedicou boa parte de sua trajetória de vida a articulação, a mobilização de apoio da sociedade de políticos com o propósito de realizar a implantação e o funcionamento da referida instituição. De acordo com o Jornal “A Conquista" (1911, s/p), como já exercia a função de professor e jornalista em Salvador, sua chegada na cidade de Conquista foi anunciada com destaque pelo jornal, cujo redator e diretor José de Souza Dantas que a ele se referia como pessoa de "espírito superior que viria morar na terra que era o berço da intelectualidade", fazendo uma alusão que circulava na cidade referências de uma cultura letrada.

No contexto das primeiras décadas do século $X X$, era de conhecimento público que os fazendeiros mais abastados contratavam pessoas, independente de profissão, com boa escolaridade e alguma habilidade pedagógica para iniciar a alfabetização, principalmente, dos filhos nas residências da cidade e da zona rural. Euclides Dantas, durante sua trajetória exercia o magistério, como profissional que ministrava aulas particulares em sua residência, tanto para criança de famílias tradicionais, como também para alunos das camadas menos abastadas da cidade que não tinham condições de pagar.

Logo após sua instalação na cidade, Euclides Dantas assumiu a redação do jornal "A Conquista" e se posicionou a favor do coronel Gugé, inclusive publicando os artigos escritos por 
Maneca Grosso - professor e intelectual, colaborador do referido jornal. De acordo Barbosa e Lima (2017, p. 1) O jornal “A Conquista” fundado em 1911, foi o primeiro periódico produzido na cidade de Vitória da Conquista, utilizado como mais um instrumento de disputa política entre coronéis da época.

De acordo Viana $(1982,76)$ o professor Euclides Dantas, era considerado um dos primeiros intelectuais de Conquista, atuou desde sua chegada até a segunda República acompanhando as mudanças políticas provenientes do cenário nacional com a chegada de Vargas ao poder e permaneceu a frente das esferas que atuava nas áreas do saber, das letras, da política, da imprensa. Sempre envolvido com a educação, prestou grande colaboração na ampliação e melhoria da instrução de Conquista: leitor, apreciador e colaborador dos jornais "O Combate", "A Luta", "A Conquista" autor da letra do hino de Vitória da Conquista e grande defensor de uma escola normal para a cidade. Desde 1932, Dantas dialogava com as lideranças políticas locais, estaduais e com intelectuais de outras regiões, buscando chamar a atenção para a necessidade de melhorar o nível de ensino do povo conquistense, que, em sua opinião, seria efetivado com a construção de uma escola voltada para a formação de professores.

É notável o empenho de Euclides Dantas na articulação de forças para defender a Escola. Brasil, (1932, p. 1) escreveu e publicou no jornal "O Combate" a notícia da viagem de Euclides para Salvador com o propósito de pleitear ao Governador Pedro Lago a construção de uma Escola Normal para Vitória da Conquista. Informações sobre Euclides, indicam que ele transitava com facilidade entre políticos e intelectuais, tal habilidade estava relacionada à excelente retórica, era considerado o orador oficial dos momentos cívicos conquistenses. Possuía um relacionamento com líderes políticos da cidade de Vitória da Conquista e outras lideranças política da capital da Bahia.

A leitura dos jornais "A Conquista, "O Combate" e a "A luta" possibilitou a identificação de memórias sobre a cidade e, particularmente, sobre a Escola Normal. Foi possível verificar como os referidos jornalistas e professores agiam, de acordo Sirinelli (1986, p. 105) como "gerações intelectuais" que eram "multiformes elásticas e espessas" e se posicionavam diante do cenário educacional apresentando concepções ideológicas que, embora diferenciadas, expressavam a visão de grupo, que partilha memórias dos modos de ser, de se relacionar e se davam a ver aos grupos com os quais dialogavam. 


\section{CONSIDERAÇÕES FINAIS}

Os intelectuais Laudionor Brasil e Euclides Dantas que tratamos nesse artigo ao lado de outros como, Eratthóstenes Menezes e Camilo de Jesus Lima, apresentam trajetórias relacionadas a cultura escrita, são jornalistas no sentido amplo, proprietário, redatores, editores, articulistas, colaboradores e professores de escolas domiciliar e pública, tabeliões, escriturários e nasceram entre 1888 e 1901. Embora tivessem formação escolar reduzida e diversa do padrão bacharelesco eles foram reconhecidos como intelectuais de grande empenho autodidata, bons oradores e mediadores culturais que se dedicaram às demandas apresentadas por grupos sociais da cidade, traduzidas neste artigo no pleito e nas articulações em defesa da construção e implantação de uma Escola Normal em Vitória da Conquista que Ihes possibilitaram, ao longo dos anos, adquirir representação política para ocupar cargos públicos, disputar e conseguir mandato no poder legislativo municipal.

Considerando que segundo Souza (2009, pp. 14-15), apesar de a cidade se construir, no final da década de 1950, de uma população de 18.017 pessoas $^{6}$ e de uma sociedade de maioria analfabeta, onde os poucos homens e mulheres que sabiam ler e escrever, tornavam-se professores e ensinavam as primeiras letras, mesmo que não tivessem a formação para exercer a profissão. É instigante observar as trajetórias dos homens que se destacaram por aprenderem a ler, escrever, comunicar e se integraram de tais formas à cultura escrita como autodidatas que exerceram as profissões de professor, diretor, jornalista, orador e atuavam com desenvoltura nos espaços da política, das letras e das artes. Nos exercícios dessas habilidades, tornaram-se reconhecidos por grupos da sociedade de Conquista como intelectuais, uma geração que, tanto pelo engajamento em demandas específicas, como foi a reivindicação da construção e funcionamento da Escola Normal, quanto pela disposição de apresentar, seguindo ou não coronéis e políticos da localidade, planos e projetos que recomendavam orientações baseadas no ideário de progresso e desenvolvimento propostos por grupos políticos e técnicos situados na estrutura do poder do Estado, prestaram, como letrados significativa contribuição a grupos de moradores de Vitória da Conquista.

Ao analisar as fontes foi possível perceber que os intelectuais mencionados estiveram envolvidos na defesa da educação, participando das campanhas em prol da criação e difusão de escolas para a sociedade de Vitória da Conquista inserida num contexto no qual o analfabetismo 
ainda era predominante, estimularam a população a frequentar as escolas, exaltavam a figura do professor, como o formador de consciências que tomaram para si a tarefa, o compromisso de difundir nacionalmente o discurso educacional formulado pela Escola Nova.

Nesse sentido, os referidos professores e jornalistas na condição de intelectuais de Conquista recorreram a meios da cultura impressa, os jornais, para defender uma escola moderna, que propunha a valorização do professor, participavam de campanhas contra o analfabetismo e eram favoráveis a construção de escolas e da discussão da educação na cidade. Assim, tornaram-se mediadores de projetos e concepções que circulavam em nível nacional, difundindo, apesar de suas contradições, além da modernização nos âmbitos educacional e político, pincipalmente, a concretização da implantação da Escola Normal apontando a educação e a formação de professores como o caminho para o desenvolvimento, modernização e progresso da nação.

\section{REFERÊNCIAS}

ALVES, Claudia. Contribuições de Jean-François Sirinelli à história dos intelectuais da educação. Revista Educação e filosofia, Uberlândia MG: IF UFU, 2019, pp. 1 a 21.

BARBOSA, Alan A. e LIMA, Marcus Antônio de A. A influência do coronelismo no jornal “A Conquista": Primeiro jornal da cidade de Vitória da Conquista. Linguagens - Revista de Letras, Artes e Comunicação. Blumenau, SC. v. 11, n. 3, p. 618-638, 2017

BRASIL, Laudionor. A falta da escola normal traz incalculável prejuízo... Jornal “O Combate”, Vitória da Conquista, ano IV, no 13, 1932.

BRASIL, Laudionor. A importância de Escola Normal para Conquista e Região. Jornal “O Combate”. Vitória da Conquista, Ano III, no 14, 1932.

BRASIL, Laudionor. Mais uma escola nunca é tarde para fazer justiça. Jornal "O Combate". Vitória da Conquista, Ano V, no 36, 1933.

BRASIL, Laudionor; DANTAS, F. A Evolução Pedagógica no Brasil. Jornal O Combate. Vitória da Conquista, Ano VII, no 1, 1935.

BUFFA, Ester e NOSELLA, Paolo. A Educação Negada: Introdução ao Estudo da Educação Brasileira Contemporânea - 2o ed. São Paulo: Cortez, 1997 - (coleção biblioteca da educação. Serie 1, escola; V. 17)

BUFFA, Ester e NOSELLA, Paolo. Instituições escolares: por que e como pesquisar. Campinas, SP: Editora Alínea, 2013. p. 89

CRUZ, Heloisa de F.; PEIXOTO, Maria do Rosário C. Na oficina do Historiador: conversas sobre História e Imprensa. In: História e Imprensa. Revista Projeto História, 35. PEPGH / DH / PUC - SP. São Paulo: EDUC, 2007.

CURY, Carlos R. Jamil. Ideologia e Educação Brasileira. 2ํo ed. São Paulo: Cortez, p. 18-19, 1984, Autores Associados (coleção educação). 
DALLABRIDA, Norberto. A reforma Francisco Campos e a modernização nacionalizada do ensino secundário. - Educação, Porto Alegre, v. 32, n. 2, p. 185-191, 2009.

DANTAS, Euclides. Régis Pacheco: esboço biográfico. Vitória da Conquista, 1976.

GRAMSCI, Antonio. Cadernos do Cárcere: Os intelectuais. O princípio educativo. Jornalismo. [Trad. Carlos Nelson Coutinho]. 5ạ. ed. Rio de Janeiro: Civilização Brasileira, 2010. Vol. 2.

LIMA, Camillo de Jesus. Homenagem a Laudionor Brasil. Jornal "O Combate", Vitória da Conquista, Ano XXXII no 37, 1960.

MEDEIROS, Rui Herman Araújo. Conquista: Poder e Conflito nos anos $\mathbf{3 0}$ do Século XX. Vitória da Conquista: Blog do Nunes, 2008. Disponível em:

http://www.blogdopaulonunes.com/noticias_especificas2008a/20080202. Acesso 20/07/2017.

NORA, Pierre. Entre Memória e História: a problemática dos lugares. Tradução [Yara Aun Khoury] Projeto História. São Paulo: EDUC, 1993, pp. 7-28

OLIVEIRA, Jeremias Macário de. A imprensa e o coronelismo no sertão do sudoeste. Vitória da Conquista: editado pelo autor, 2005.

PADRE, Mario. A Evolução pedagógica no Brasil. Jornal O Combate. Vitória da Conquista. Ano VII no 1,11 de agosto de 1935

PEREIRA, A. A educação de jovens e adultos no sistema prisional brasileiro: o que dizem os planos estaduais de educação em prisões? Revista Tempos e Espaços em Educação, v. 11, n. 24, p. 245252, 19 jan. 2018. Disponível em: https://seer.ufs.br/index.php/revtee/article/view/6657

SAVIANI, Dermeval. História da formação docente no Brasil: três momentos decisivos. Educação, Santa Maria- RS, v. 30, n. 2. 2005.

SILVA, Paulo Santos. Âncoras de tradição. Luta política, intelectuais e construção do discurso histórico na Bahia (1930-1949). Salvador: EDUFBA, 2000.

SIRINELLI, Jean-François. As elites culturais. In: RIOUX, Jean-Pierre e SIRINELLI, Jean-François. Para uma história cultural. Lisboa, Editorial Estampa 1998.

SIRINELLI, Jean-François. Le hazard ou la necessité? Une histoire en chantier: I'histoire des intellectuels. Vingtième siècle. Revue d'Histoire, Paris: Sciences Po University Press, n. 9, p. 97108, 1986. Disponível em http://www.jstor.org/stable/3768995. Acesso em 20-03-2018

SOUSA, Maria Aparecida S. de; BORBOREMA, Carlos G. Literatura e política: a trajetória de um poeta militante no interior da Bahia (1930-1975). In: Revista Politéia: história e sociedade. Vitória da Conquista: [s.n], v.1 n.1, p. 225-246, 2001.

SOUZA, Daniela Moura R. de. CASIMIRO, Ana Palmira B. S. Não fazem mal as musas aos alfaiates: um professor intelectual em Vitória da Conquista - Ba. O caso de Laudionor de Andrade Brasil. Revista HISTEDBR On-line, Campinas, SP, 2010.

SOUZA, Daniela Moura R. de. MAGALHÃES, Lívia Diana R.: A megera está rondando... Camilo de Jesus Lima um professor intelectual em Vitória da Conquista- Ba no primeiro governo de Vargas (1930-1945). Revista HISTEDBR On-line, Campinas, no 61, p. 306-321, mar 2015.

SOUZA, Daniela Moura Rocha de. Memória de Professores Intelectuais como interlocutores do republicanismo em Vitória da Conquista -Ba de 1910 até 1945. [dissertação]. Vitória da Conquista: Programa de Pós-Graduação Memória: Linguagem e Sociedade-UESB, 2009. 
VIANA, Aníbal Lopes. A Instrução em Vitória da Conquista em 1930 In: Revista Histórica de Conquista. Vitória da Conquista. V. II p. 455, S/d

VIANA, Aníbal Lopes. Revista histórica de Vitória da Conquista. Vitória da Conquista. Ed. do autor. Brasil Artes Gráficas LTDA. vol. I, v. 2, 1982.

\section{SOBRE OS AUTORES}

\section{Gilmario Moreira Brito}

Doutor em História Social / PUC/SP, Professor Titular Universidade do Estado da Bahia / Departamento de Educação / Programa de Pós-Graduação Educação e Contemporaneidade. Salvador, BA, BR. Coordenador do GEHCEL- Grupo de Estudos Educação, História, Cultura e Linguagens.

E-mail: gilmariobrito@gmail.com

ORCID: http://ORCID.org/0000-0001-9349-1993

\section{Maria Gamaliélia do Socorro Limeira Coutinho}

Mestra em Educação e Contemporaneidade, Universidade do Estado da Bahia/ Departamento de Educação / Programa de Pós-Graduação Educação e Contemporaneidade. Salvador BA, BR. Professora da Rede Municipal de Ensino de Vitória da Conquista - BA, BR. Participante - GEHCEL.

E-mail: gamalielia@hotmail.com

ORCID: http://ORCID.org/0000-0002-9856-0166 